\title{
The relationship between self-disgust, guilt, and flow experience among Japanese undergraduates
}

This article was published in the following Dove Press journal:

Neuropsychiatric Disease and Treatment

16 July 2013

Number of times this article has been viewed

\section{Kazuki Hirao \\ Ryuji Kobayashi}

Department of Occupational Therapy, School of Health Science and Social Welfare, Kibi International University, Okayama, Japan
Correspondence: Kazuki Hirao Kibi International University, 8 Iga-machi, Takahashi, Okayama 716-8508, Japan

Tel +8I 866224044

Fax +8I 866224044

Email hirao-k@kiui.ac.jp
Purpose: To determine the relationship between self-disgust, guilt, and flow experience.

Methods: A cross-sectional survey was conducted in a convenience sample of 142 Kibi International University students (mean age, 20.09 \pm 1.24 years; 85 males and 57 females). Each participant was evaluated using the Flow Experience Checklist, Self-Disgust Scale, and Situational Guilt Inventory. Correlation analysis was used to describe the strength and direction of the relationship between variables. We employed Pearson's partial correlations, adjusted for age and sex, using dummy variables (female $=0$, male $=1$ ).

Results: Analysis of the relationship between the frequency of flow experience and the SelfDisgust Scale scores showed a statistically significant negative correlation, whereas the duration of the activity and the Situational Guilt Inventory score showed a significant positive correlation. The quality of flow experience and the Situational Guilt Inventory score showed a significant positive correlation.

Conclusion: These findings suggest that flow experience could be helpful for those who need treatment to reduce negative emotions.

Keywords: negative emotion, mental health, positive psychology

\section{Introduction}

The state in which people are so intensely involved in an activity that nothing else seems to matter, and the experience of which can become so highly enjoyable that even at a great cost, people continue for the sheer sake of the experience, is known as flow. ${ }^{1}$ Flow enhances positive subjective experiences. ${ }^{1}$ Flow plays a central role in the area of positive psychology, ${ }^{2}$ and flow experiences have also been widely applied in the fields of sociology, business administration, education, and sport. ${ }^{3}$

We have the following evidence regarding flow: (1) a significant correlation was observed between the frequency of the flow experiences and general health perception, social functioning, and mental health; ${ }^{4}(2)$ subjective stress was significantly reduced in a high-score (high-flow) group compared with that of a low-score (low-flow) group, thereby suggesting that a high flow experience is effective for reducing subjective stress; ${ }^{5}(3)$ ambiguity tolerance and shyness have been associated with the frequency and quality of the flow experience, ${ }^{6}$ and (4) physical health is significantly better in groups who experience flow during important daily activities than in an apathetic group. ${ }^{7}$

Based on these findings, we hypothesized that a flow experience exerts a positive influence on subjective stress and health-related quality of life, but we were also interested to know whether the flow experience has a limiting effect on negative feelings. In addition, Mosing et al have recently suggested that individuals who 
are genetically predisposed to experience flow, show less behavioral inhibition and feel that they are in control of their own destiny. ${ }^{8}$

In a previous study, excessive guilt was found to be significantly associated with suicide attempt. ${ }^{9}$ In Japan, out of 18,104 students $(8,620$ were $12-15$ years of age; 9,484 were 15-18 years of age), 276 (3.3\%) of the junior and 396 $(4.3 \%)$ of the senior high school students reported to have self-harmed. ${ }^{10}$ Moreover, self-disgust appears to mediate the relationship between dysfunctional cognition and depressive symptomatology, thus demonstrating that self-disgust plays a role in depression. ${ }^{11}$ Therefore, suppression of guilt and self-disgust is a very important issue in human life. However, the relationship between flow, guilt, and self-disgust has not been clarified completely.

The objective of this study was to investigate the relationship between the flow experience, self-disgust, and guilt, among university students.

Increased knowledge of the interaction between selfdisgust, guilt, and the flow experience could help identify treatments for human health care management.

\section{Material and methods Design}

A cross-sectional survey of the relationship between selfdisgust, guilt, and flow experience was conducted in Japan.

\section{Participants}

The study population was a convenience sample of 152 healthy university students in Okayama, Japan (mean age, $20.01 \pm 1.38$ years; 89 males and 63 females). All participants provided their written informed consent and were assured anonymity.

\section{Data collection}

We distributed a questionnaire to the participants in a lecture room and explained the questionnaire in detail. Upon completion, the questionnaires were immediately collected from the participants. This questionnaire survey was conducted after a regular lecture.

\section{Instruments}

\section{Flow Experience Checklist}

This scale consists of one item that measures the tendency of a person to experience flow during daily life and ten items that assess the nature of the flow experience when the activity has an intrinsic reward. This checklist was evaluated on a seven-point scale.
One item provided an index of the frequency of flow experiences in a person's life, wherein a higher score indicated more daily flow experiences. The other ten items measured the quality of the flow experience. In addition, the time taken for the important activities of daily life per week was measured. The reliability and validity of this scale have been confirmed previously. ${ }^{12}$

\section{Self-Disgust Scale}

In the Self-Disgust Scale, self-disgust is rated on the basis of whether one recognizes a negative feeling or phenomenon related to the self and feels disgusted. ${ }^{13}$

This scale consisted of one factor and contained 21 items (scored on a five-point scale). A higher score indicated more self-disgust. The reliability and validity of this scale have been confirmed previously. ${ }^{13}$

\section{Situational Guilt Inventory (SGI)}

This scale consisted of four factors (hurting others, inconsiderate of others, acting selfishly, and feeling indebted toward others). This scale contains 31 items (scored on a four-point scale).

The reliability and validity of this scale have been confirmed previously. ${ }^{14}$ We used the total score of the 31 items, based on a method suggested by Arimitsu. ${ }^{15} \mathrm{~A}$ high score indicated a tendency to experience a sense of guilt.

\section{Statistical analysis}

Descriptive statistics were calculated for each variable. We analyzed the relationships between the Flow Experience Checklist score and the Self-Disgust Scale score and between the Flow Experience Checklist and the SGI score. A correlation analysis was used to describe the strength and direction of the relationship between variables. We employed Pearson partial correlations, which were adjusted for age and sex using dummy variables (female $=0$, male $=1$ ).

SPSS Statistics for Windows, Version 19 software (IBM, Armonk, NY, USA) was employed for all analyses. Results were represented as mean \pm standard deviation (SD), and a two-sided value of $P<0.05$ was considered to be statistically significant.

\section{Results}

\section{Characteristics of study participants}

We excluded ten participants with missing values on measurement parameters. Therefore, in total, 142 participants were analyzed; mean age, $20.09 \pm 1.24$ years; 85 males and 57 females. 
Table 1 shows the mean values and SDs for the measurements of the study participants. The mean frequency of flow experiences was $4.7 \pm 1.17$, and the mean duration of the activity (hours/week) was $10.36 \pm 8.94$. The mean quality of the flow experience was $46.27 \pm 6.66$. The mean Self-Disgust Scale score was $66.03 \pm 22.03$, and the mean SGI score was $102.71 \pm 12.32$.

The correlations between self-disgust, guilt, and flow experience of the participants are shown in Table 2 . A significant negative correlation was observed between the frequency of the flow experience and the Self-Disgust Scale score $(r=-0.242 ; P=0.004)$. A statistically significant correlation was observed between the duration of activity and SGI score $(r=0.200 ; P=0.019)$, and between the quality of the flow experience and the SGI score $(r=0.209 ; P=0.014)$.

\section{Discussion}

\section{Flow experience and self-disgust}

A negative correlation was observed between the Self-Disgust Scale score and the frequency of flow experiences; the frequency of the flow experience and level of self-disgust are mutually related. Self-disgust is defined as a negative feeling and is related to a lack of confidence. ${ }^{16}$ In contrast, because confidence in one's capability occurs in a positive situation, a negative correlation was observed between the Self-Disgust Scale score and the frequency of flow experiences. In addition, the flow experience has been found to be a strong influence in compulsive behavior addiction, ${ }^{17}$ and it has been suggested that in pursuing the flow experience, the addict enjoys being devoted to the certain subject that can lower self-disgust. Moreover, according to a previous study on post-traumatic stress disorder (PTSD), playing "Tetris" produced a significant reduction in flashback frequency after 1 week. ${ }^{18}$ This was thought to have occurred because "unnecessary memories" were reduced in the dedication to the Tetris activity. Thus, it is possible that unnecessary memories related to self-disgust are reduced by being devoted to a subject.

Besides Tetris of course, other "addictive" activities include sports, such as volleyball ${ }^{4}$ and listening to music. ${ }^{5}$

Table I Result of measurements of the study participants

\begin{tabular}{lr}
\hline Measurements & Participants \\
\hline Flow Experience Checklist & \\
Frequency of flow experience & $4.7 \pm 1.17$ \\
Duration of the activity (hours per week) & $10.36 \pm 8.94$ \\
Quality of flow experience & $46.27 \pm 6.66$ \\
Self-Disgust Scale score & $66.03 \pm 22.03$ \\
Situational Guilt Inventory score & $102.71 \pm 12.32$ \\
\hline
\end{tabular}

Note: Data are presented as mean values \pm standard deviations.
Table 2 Correlations between the self-disgust, guilt, and flow experience

\begin{tabular}{lll}
\hline & $\begin{array}{l}\text { Self-Disgust } \\
\text { Scale score }\end{array}$ & $\begin{array}{l}\text { Situational Guilt } \\
\text { Inventory score }\end{array}$ \\
\hline Flow Experience Checklist & & \\
Frequency of flow experience & $-0.242^{* *}$ & 0.064 \\
Duration of the activity (h/wk) & 0.056 & $0.200^{*}$ \\
Quality of flow experience & -0.077 & $0.209 *$ \\
\hline
\end{tabular}

Notes: We employed Pearson partial correlations, adjusted for age and sex. $* P \leq 0.05 ; * * P \leq 0.01$.

As healthy university students participated in this study, we considered similar outcomes might be found in the wider population of health consumers.

\section{Flow experience and guilt}

A correlation was observed between the SGI score and the duration of the flow experience. A correlation was also observed between the SGI score and the quality of the flow experience, demonstrating that the length and the quality of the flow experience and sensitivity to guilty feelings are mutually related. We concluded from this that those who experience guilt are motivated to compensate for their bad actions ${ }^{19}$ and thus have long and high quality flow experiences. Moreover, the study findings are consistent with the work of Depue et al, ${ }^{20}$ in which a negative image was shown to participants who were then directed to remember it positively. In that study, magnetic resonance imaging clearly revealed that the domain relevant to emotional information of the memory representation is controlled by a part of the prefrontal area and that the domain relevant to the memory and emotions is similarly controlled. It has been suggested that this domain can intentionally control emotional memory. Individuals experiencing guilty feelings often take a long time to intentionally experience a flow. Therefore, it has been suggested that this flow experience may be oriented to improve its quality. Again, as healthy university student participated in our study, we considered this could also be true in the wider population of health consumers.

This study had at least three limitations. First, our data were from a cross-sectional survey, and this prevents us from discussing causality between variables. Therefore, a longitudinal study should be conducted in the future. Second, as the correlation coefficients between variables were approximately 0.2 , suggesting weak correlations, a cautious interpretation of the results is necessary. Participants included were only from one university, so the results cannot be generalized. Further, the weak correlation observed might be due to the small sample size. Finally, there may be other 
factors that influence university student participants. We employed Pearson partial correlations, which were adjusted for age and sex using dummy variables.

It will be necessary to scrutinize and control for possible confounding factors (eg, home environment, sleep time, interpersonal relationships, etc) in the future.

\section{Conclusion}

There were correlations found in the relationships between the frequency of flow experience and self-disgust; the duration of the flow activity and guilt; and the quality of flow experience and guilt. Therefore it is important to promote the experience of flow in daily life. These findings suggest that a flow experience could be helpful for those who need treatment, to reduce negative emotions.

\section{Disclosure}

The authors report no conflicts of interest in this work.

\section{References}

1. Csikszentmihalyi M. Flow: The Psychology of Optimal Experience. New York, NY: Harper and Row; 1990.

2. Fullagar CJ, Kelloway EK. Flow at work: An experience sampling approach. J Occup Organ Psychol. 2009;82(3):595-615.

3. Hirao K, Kobayashi R. Flow experience in daily living and health-related quality of life. In: Giroux JP, Vallee C, editors. Activities of Daily Living: Performance, Impact on Life Quality and Assistance. New York, NY: Nova Science Publishers; 2013:169-174.

4. Hirao K, Kobayashi R, Okishima K, Tomokuni Y. Influence of flow experience during daily life on health-related quality of life and salivary amylase activity in Japanese college students. JJOMT. 2011;59(1): $13-18$.

5. Hirao K, Kobayashi R, Okishima K, Tomokuni Y, Yabuwaki K. Influence of different intensities of brief flow experiences on subjective and objective stress. Medicine and Biology. 2011;155(10):713-720. Available from http://ci.nii.ac.jp/naid/40019018652. Accessed February 12, 2012.
6. Hirao K, Kobayashi R, Yabuwaki K. Association of cognitive judgment and shyness with frequency and quality of flow experience. Psychol Res Behav Manag. 2012;5:159-162.

7. Hirao K, Kobayashi R, Okishima K, Tomokuni Y. Flow experience and health-related quality of life in community dwelling elderly Japanese. Nurs Health Sci. 2012;14(1):52-57.

8. Mosing MA, Pedersen NL, Cesarini D, et al. Genetic and environmental influences on the relationship between flow proneness, locus of control and behavioral inhibition. PLOS ONE. 2012;7(11):e47958.

9. Bi B, Xiao X, Zhang H, et al. A comparison of the clinical characteristics of women with recurrent major depression with and without suicidal symptomatology. Psychol Med. 2012;42(12):2591-2598.

10. Watanabe N, Nishida A, Shimodera S, et al. Help-seeking behavior among Japanese school students who self-harm: results from a selfreport survey of 18,104 adolescents. Neuropsychiatr Dis Treat. 2012;8: 561-569.

11. Overton PG, Markland FE, Taggart HS, Bagshaw GL, Simpson J. Selfdisgust mediates the relationship between dysfunctional cognitions and depressive symptomatology. Emotion. 2008;8(3):379-385.

12. Ishimura I, Kodama M. Flow experience in activities with intrinsic rewards and relation with emotional state. Proceedings of the 14th Congress of Japanese Society of Research on Emotions; 2006. Japanese.

13. Mizuma R. The construction of self-disgust scale. Kyoiku Shinrigaku Kenkyu. 1996;44(3):296-302. Japanese.

14. Arimitsu K. Structure of guilt eliciting situations in Japanese adolescents. Shinrigaku Kenkyu. 2002;73(2):148-156. Japanese.

15. Arimitsu K. Guilt, shame/embarrassment, and empathy. Shinrigaku Kenkyu. 2006;77(2):97-104. Japanese.

16. Satoh Y. Self-Disgust and self-affirmation in university students. Jpn J Educ Psychol. 2001;49(3):347-358. Japanese.

17. Chou TJ, Ting CC. The role of flow experience in cyber-game addiction. Cyberpsychol Behav. 2003;6(6):663-675.

18. Holmes EA, James EL, Coode-Bate T, Deeprose C. Can playing the computer game "Tetris" reduce the build-up of flashbacks for trauma? A proposal from cognitive science. PLoS ONE. 2009;4(1):e4153.

19. Tangney JP, Burggraf SA, Wagner PE. Shame-proneness, guiltproneness, and psychological symptoms. In: Tangney JP, Fischer KW, editors. Self-Conscious Emotions: The Psychology of Shame, Guilt, Embarrassment, and Pride. New York, NY: Guilford Press; 1995: 343-367.

20. Depue BE, Curran T, Banich MT. Prefrontal regions orchestrate suppression of emotional memories via a two-phase process. Science. 2007;317(5835):215-219.
Neuropsychiatric Disease and Treatment

\section{Publish your work in this journal}

Neuropsychiatric Disease and Treatment is an international, peerreviewed journal of clinical therapeutics and pharmacology focusing on concise rapid reporting of clinical or pre-clinical studies on a range of neuropsychiatric and neurological disorders. This journal is indexed on PubMed Central, the 'PsycINFO' database and CAS.

\section{Dovepress}

The manuscript management system is completely online and includes a very quick and fair peer-review system, which is all easy to use. Visit http://www.dovepress.com/testimonials.php to read real quotes from published authors. 